\title{
Total Cholesterol and Neuropsychiatric Symptoms in Alzheimer's Disease: The Impact of Total Cholesterol Level and Gender
}

\author{
James R. Hall ${ }^{a, b}$ April R. Wiechmann ${ }^{a, b}$ Leigh A. Johnson ${ }^{a, c}$ \\ Melissa Edwards ${ }^{e}$ Robert C. Barber ${ }^{a}, d$ Rebecca Cunningham ${ }^{a}$ d \\ Meharvan Singh ${ }^{a, d}$ Sid E. O'Bryant ${ }^{a, c}$ for the Texas Alzheimer's Research \\ and Care Consortium \\ anstitute of Aging and Alzheimer's Disease Research, and Departments of b Psychiatry and \\ Behavioral Health, ' Internal Medicine and ${ }^{\mathrm{d}}$ Pharmacology and Neuroscience, University \\ of North Texas Health Science Center, Fort Worth, Tex., and 'Department of Psychology, \\ University of North Texas, Denton, Tex., USA
}

\author{
Key Words \\ Cholesterol · Neuropsychiatric symptoms · Alzheimer's disease
}

\begin{abstract}
Background: Neuropsychiatric symptoms (NPS) in Alzheimer's disease (AD) are a major factor in nursing home placement and a primary cause of stress for caregivers. Elevated cholesterol has been linked to psychiatric disorders and has been shown to be a risk factor for AD and to impact disease progression. The present study investigated the relationship between cholesterol and NPS in AD. Methods: Data on cholesterol and NPS from 220 individuals (144 females, 76 males) with mild-to-moderate AD from the Texas Alzheimer's Research and Care Consortium (TARCC) cohort were analyzed. The total number of NPS and symptoms of hyperactivity, psychosis, affect and apathy were evaluated. Groups based on total cholesterol (TC; $\geq 200$ vs. $<200 \mathrm{mg} / \mathrm{dl}$ ) were compared with regard to NPS. The impact of gender was also assessed. Results: Individuals with high TC had lower MMSE scores as well as significantly more NPS and more symptoms of psychosis. When stratified by gender, males with high TC had significantly more NPS than females with high TC or than males or females with low TC. Conclusion: The role of elevated cholesterol in the occurrence of NPS in AD appears to be gender and symptom specific. A cross-validation of these findings will have implications for possible treatment interventions, especially for males with high TC.

(C) 2014 S. Karger AG, Basel
\end{abstract}




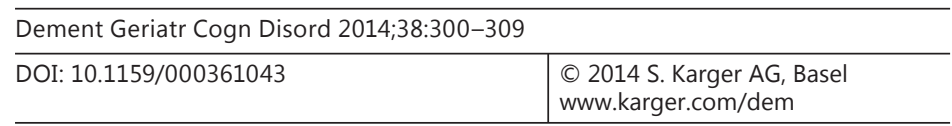

Hall et al.: Total Cholesterol and Neuropsychiatric Symptoms in Alzheimer's Disease: The Impact of Total Cholesterol Level and Gender

\section{Introduction}

The findings on the relationship of total cholesterol (TC) to Alzheimer's disease (AD) have been inconsistent. High cholesterol during midlife has been found to increase the risk for $\mathrm{AD}$ [1-3] as well as to impact disease progression in the elderly [4-6]. Recent work has provided evidence relating an altered cholesterol metabolism and hypercholesterolemia to amyloid plaque formation and tau hyperphosporylation [7]. Even mild hypercholesterolemia has been linked to AD pathology [8]. However, other studies have found an association between higher cholesterol in late life and a reduced risk for dementia $[9,10]$. The HonoluluAsia Aging Study showed that cholesterol levels decline before the onset of dementia [11]. Still others have found significantly lower levels of TC in a community-dwelling sample of demented elderly individuals [12], and the results of one study indicated no relationship between cholesterol and the risk for cognitive decline in the elderly [13].

Although there is no consensus on the role of cholesterol in the development of dementia, a large body of experimental and epidemiological research continues to focus on this potentially modifiable risk. The link between cholesterol and neuropsychiatric symptoms (NPS) in $\mathrm{AD}$ has not been extensively investigated. Woods et al. [14] suggested that disturbances in the cholesterol system may be a significant factor in the development of psychiatric disorders such as schizophrenia, autistic spectrum disorders and depression as well as AD. The mechanism through which serum cholesterol affects brain cholesterol and brain pathology is unclear at this time $[15,16]$. It has been argued that high cholesterol triggers an inflammatory cascade that influences amyloid beta production [17]. Neuroinflammation has also been linked to a number of psychiatric disorders such as depression, schizophrenia and bipolar disorder [18]. The impact of cholesterol on inflammatory processes may be one possible pathway by which high serum cholesterol may affect the occurrence of NPS in AD.

In previous work [19], our group studied the relationship between inflammatory and clinical vascular risk biomarkers and the occurrence of NPS in mild-to-moderate AD. Regression analyses found total serum cholesterol to be a significant predictor of NPS, but this relationship held only for males. We also found that APOE\&4 status was not a significant factor in this relationship as cholesterol was a significant predictor for both male carriers and noncarriers [20]. The present study was conducted to investigate the extent to which the level of cholesterol is the primary determinant of the relationship between serum cholesterol and NPS. Additionally, we sought to examine the role of gender in this relationship. A TC level of $\geq 200 \mathrm{mg} / \mathrm{dl}$ has been widely used as a clinical cutoff [21] for the diagnosis of borderline high cholesterol. In the current study, individuals diagnosed with mild-to-moderate AD were separated into two groups based on their total serum cholesterol levels, and the impact of cholesterol on the occurrence of NPS was assessed.

\section{Materials and Methods}

\section{Participants}

The sample was drawn from the individuals enrolled in the longitudinal research cohort of the Texas Alzheimer's Research Care and Consortium (TARCC) who had complete serum biomarker panels, were genotyped for APOE\&4 status and had completed a Neuropsychiatric Inventory (NPI) interview. The TARCC is a longitudinal multisite study of a cohort of individuals with $\mathrm{AD}$, subjects with mild cognitive impairment and normal controls in which each participant undergoes an annual evaluation that includes a medical examination, an interview, neuropsychological testing and a blood draw. The AD patients received a consensusbased diagnosis of probable AD based on NINCDS-ADRDA criteria [22].

The final sample of 220 individuals consisted of 144 females and 76 males meeting the diagnostic criteria for AD. As part of the evaluation, the MMSE, a screening measure of cognitive functioning, was administered. A global dementia rating (CDR-Global) based on interview data was determined along with the CDR 
Hall et al.: Total Cholesterol and Neuropsychiatric Symptoms in Alzheimer's Disease:

The Impact of Total Cholesterol Level and Gender

Sum of Boxes (CDR-SB) score, which is a measure of functional impairment where higher scores indicate greater impairment. The mean age of the sample was 77.55 years ( $\mathrm{SD}=8.416)$, with an average education of 14.11 years (SD = 3.203), a mean MMSE score of 19.09 (SD = 6.202), a mean CDR-Global score of 1.35 (SD = 0.766 ) and a mean CDR-SB score of 7.95 (SD = 4.413). Genotyping revealed that $59 \%$ of the sample were APOE 4 carriers and $41 \%$ were noncarriers. The total years of education were determined from the patients' self-reports of completed years of education. Institutional review board approval was obtained from each TARCC site, and written informed consent was obtained from all participants and/or caregivers.

Methods

As part of the TARCC evaluation, the NPI Questionnaire (NPI-Q) was administered to family members or to caregivers with direct knowledge of the participants' behavior. The NPI-Q is a brief informant-based assessment of NPS that has been shown to be valid and reliable [23]. The informant reports on the presence of 12 NPS and rates their severity on a scale from 1 (mild) to 3 (severe). As in our previous research [19, 20], we utilized the 4 factors found by Aalten et al. [24]. This factor structure was based on a total NPI score (sum of each item multiplied by its severity score); however, we chose to utilize only the total number of NPS as our focus was on the occurrence of the symptoms, not on their perceived severity. The 4 NPI factors are the following: (1) the hyperactivity factor, composed of the NPI items of agitation, disinhibition, irritability, aberrant motor behavior and euphoria; (2) the psychosis factor, which includes delusions, hallucinations and night-time behavioral disturbances; (3) the affective symptoms factor, made up of depression and anxiety items, and (4) the apathy factor, which includes the items of apathy, appetite and eating abnormalities. Data were recorded for the presence of each of these 12 NPS, and the items were summed to produce a score for the total number of symptoms. The numbers of symptoms reported for each factor were summed and made up the score for each factor.

Biomarkers

The TARCC research platform used the Rules-Based Medicine multiplexed immunoassay Multi-Analyte Profile (HumanMAP), which is able to simultaneously assay over 152 serum-based biomarkers. This platform has been utilized in the development of blood-based algorithms for the detection of AD [25] and the development of test-specific blood-based algorithms for cognitive impairment [26]. For the current study, TC was the biomarker of interest as our earlier work found that components of HDL, LDL and triglycerides individually were not significant predictors of NPS. Baseline lipid profiles and homocysteine levels of the participants were obtained by collaboration with the Atherosclerosis Clinical Research Laboratory at Baylor College of Medicine.

Assays

Nonfasting samples were collected with $10-\mathrm{ml}$ serum-separating (tiger top) vacutainer tubes at the time of the interview. The samples were allowed to clot at room temperature for $30 \mathrm{~min}$ in a vertical position before being centrifuged at 1,300 $\mathrm{g}$ for $10 \mathrm{~min}$. Next, 1-ml aliquots were pipetted into polypropylene cryovial tubes and placed in $-20^{\circ} \mathrm{C}$ (non-frost free) or $-80^{\circ} \mathrm{C}$ freezers until shipment to the TARCC Biobank. The total processing time (stick to freezer) was $\leq 2 \mathrm{~h}$. Baseline lipid profiles and homocysteine levels of the participants were obtained through the Atherosclerosis Clinical Research Laboratory at Baylor College of Medicine. The lipids were measured in serum, using an AU400e automated chemistry analyzer (Olympus America, Center Valley, Pa., USA).

\section{Data Analysis}

The participants with a total serum cholesterol level $\geq 200 \mathrm{mg} / \mathrm{dl}$ were defined as belonging to the high-TC group. Those with a level $<200 \mathrm{mg} / \mathrm{dl}$ were classified as the low-TC group. Categorical data were analyzed by $\chi^{2}$ goodness-of-fit tests, and differences in demographic variables, NPI scores and cholesterol levels were analyzed by $t$ tests and multivariate analysis of variance. Odds ratios (OR) for the presence and absence of NPS were calculated.

\section{Results}

Table 1 presents the demographic characteristics of the total sample split by gender and cholesterol level. The female sample was significantly older than the male sample [F(1, $219)=11.842, p=0.001]$. There were no significant differences observed between males and 


\section{Dementia}

Cognitive Disorders
Dement Geriatr Cogn Disord 2014;38:300-309

\begin{tabular}{l|l}
\hline DOI: $10.1159 / 000361043$ & (C) 2014 S. Karger AG, Basel
\end{tabular} www.karger.com/dem

Hall et al.: Total Cholesterol and Neuropsychiatric Symptoms in Alzheimer's Disease: The Impact of Total Cholesterol Level and Gender

Table 1. Sample characteristics by gender and TC level

\begin{tabular}{|c|c|c|c|c|c|c|c|c|}
\hline & \multicolumn{2}{|c|}{ Total sample } & \multicolumn{3}{|l|}{ Male } & \multicolumn{3}{|l|}{ Female } \\
\hline & $\begin{array}{l}\mathrm{TC} \geq 200 \\
\mathrm{mg} / \mathrm{dl} \\
(\mathrm{n}=133)\end{array}$ & $\begin{array}{l}\mathrm{TC}<200 \\
\mathrm{mg} / \mathrm{dl} \\
(\mathrm{n}=87)\end{array}$ & $\begin{array}{l}\text { total } \\
\text { sample } \\
(n=76)\end{array}$ & $\begin{array}{l}\mathrm{TC} \geq 200 \\
\mathrm{mg} / \mathrm{dl} \\
(\mathrm{n}=33)\end{array}$ & $\begin{array}{l}\mathrm{TC}<200 \\
\mathrm{mg} / \mathrm{dl} \\
(\mathrm{n}=43)\end{array}$ & $\begin{array}{l}\text { total } \\
\text { sample } \\
(\mathrm{n}=144)\end{array}$ & $\begin{array}{l}\mathrm{TC} \geq 200 \\
\mathrm{mg} / \mathrm{dl} \\
(\mathrm{n}=100)\end{array}$ & $\begin{array}{l}\mathrm{TC}<200 \\
\mathrm{mg} / \mathrm{dl} \\
(\mathrm{n}=44)\end{array}$ \\
\hline Age, years & $78.38 \pm 8.8$ & $76.78 \pm 0.7$ & $75.31 \pm 8.4$ & $74.24 \pm 8.8$ & $76.17 \pm 8.1$ & $78.73 \pm 8.1$ & $77.65 \pm 8.6$ & $81.11 \pm 6.3$ \\
\hline Education, years & $14.31 \pm 3.3$ & $13.81 \pm 2.9$ & $14.49 \pm 3.2$ & $14.52 \pm 3.2$ & $14.46 \pm 3.0$ & $13.91 \pm 3.1$ & $14.24 \pm 3.2$ & $13.20 \pm 2.8$ \\
\hline MMSE score & $17.96 \pm 6.4$ & $20.82 \pm 5.3$ & $19.55 \pm 7.0$ & $15.85 \pm 7.4$ & $22.54 \pm 5.1$ & $18.85 \pm 5.7$ & $18.68 \pm 5.9$ & $19.23 \pm 5.1$ \\
\hline CDR-Global score & $1.45 \pm 0.7$ & $1.15 \pm 0.7$ & $1.25 \pm 0.7$ & $1.42 \pm 0.7$ & $0.99 \pm 0.7$ & $1.43 \pm 1.0$ & $1.48 \pm 1.1$ & $1.31 \pm 0.9$ \\
\hline CDR-SB score & $8.67 \pm 4.3$ & $6.84 \pm 4.3$ & $7.15 \pm 4.5$ & $9.17 \pm 4.4$ & $5.52 \pm 4.0$ & $8.37 \pm 4.2$ & $8.51 \pm 4.3$ & $8.07 \pm 4.2$ \\
\hline \multicolumn{9}{|l|}{ APOEc4 status } \\
\hline carriers/noncarriers, $\%$ & $62 / 38$ & $49 / 51$ & $44 / 56$ & $49 / 51$ & $43 / 57$ & $65 / 35$ & $67 / 33$ & $60 / 40$ \\
\hline
\end{tabular}

Table 2. NPS by gender and TC level

\begin{tabular}{cccccc}
\hline & NPI total & Hyperactivity & Psychosis & Affect & Apathy \\
\hline Total sample $(\mathrm{n}=220)$ & $3.98 \pm 2.63$ & $1.49 \pm 1.32$ & $0.75 \pm 0.83$ & $0.87 \pm 0.80$ & $0.82 \pm 0.75$ \\
TC $\geq 200 \mathrm{mg} / \mathrm{dl}(\mathrm{n}=133)$ & $4.26 \pm 2.60$ & $1.60 \pm 1.28$ & $0.87 \pm 0.81$ & $0.89 \pm 0.81$ & $0.85 \pm 0.75$ \\
TC $<200 \mathrm{mg} / \mathrm{dl}(\mathrm{n}=87)$ & $3.56 \pm 2.65$ & $1.32 \pm 1.38$ & $0.55 \pm 0.67$ & $0.85 \pm 0.79$ & $0.77 \pm 0.74$ \\
Total male sample (n= 76) & $4.20 \pm 2.93$ & $1.67 \pm 1.34$ & $0.74 \pm 0.89$ & $0.87 \pm 0.75$ & $0.84 \pm 0.78$ \\
TC $\geq 200 \mathrm{mg} / \mathrm{dl}(\mathrm{n}=33)$ & $5.24 \pm 2.96$ & $1.97 \pm 1.33$ & $1.09 \pm 1.01$ & $1.09 \pm 0.77$ & $1.03 \pm 0.73$ \\
TC $<200 \mathrm{mg} / \mathrm{dl}(\mathrm{n}=43)$ & $3.40 \pm 2.67$ & $1.44 \pm 1.32$ & $0.47 \pm 0.67$ & $0.70 \pm 0.71$ & $0.70 \pm 0.80$ \\
Total female sample (n=144) & $3.86 \pm 2.47$ & $1.40 \pm 1.31$ & $0.75 \pm 0.81$ & $0.88 \pm 0.83$ & $0.81 \pm 0.73$ \\
TC $\geq 200 \mathrm{mg} / \mathrm{dl}(\mathrm{n}=100)$ & $3.93 \pm 2.40$ & $1.48 \pm 1.24$ & $0.80 \pm 0.84$ & $0.82 \pm 0.82$ & $0.79 \pm 0.76$ \\
TC $<200 \mathrm{mg} / \mathrm{dl}(\mathrm{n}=44)$ & $3.71 \pm 2.66$ & $1.21 \pm 1.44$ & $0.64 \pm 0.72$ & $1.00 \pm 0.84$ & $0.84 \pm 0.68$ \\
\hline
\end{tabular}

Values denote means \pm SD.

females in years of education, MMSE score, CDR-Global score or CDR-SB score. The females had significantly higher levels of TC (mean $=220.78 \mathrm{mg} / \mathrm{dl}, \mathrm{SD}=49.343)$ than the males $[$ mean $=189.24 \mathrm{mg} / \mathrm{dl}, \mathrm{SD}=40.692 ; \mathrm{t}(218)=4.761, \mathrm{p} \leq 0.0001]$. Significantly more females than males had TC $\geq 200 \mathrm{mg} / \mathrm{dl}\left[\chi^{2}(1)=14.091, \mathrm{p}=0.0002\right]$. The females in the high-TC group had significantly higher levels of cholesterol (mean $=243.41 \mathrm{mg} / \mathrm{dl}, \mathrm{SD}=41.335)$ than the males in the high-TC group [mean $=227.24 \mathrm{mg} / \mathrm{dl}, \mathrm{SD}=26.686 ; \mathrm{t}(133)=2.104, \mathrm{p}=0.0373$ ] There was no difference between APOE 4 carriers and noncarriers in cholesterol level $\left[\chi^{2}(1)=1.739, p=0.187\right]$. When analyzed by gender, no differences in cholesterol level were found between APOE 44 carriers and noncarriers for either males $\left[\chi^{2}(1)=0.020, p=0.888\right]$ or females $\left[\chi^{2}(1)=0.529, p=0.469\right]$.

The high-TC and the low-TC groups did not differ significantly in age or education. The MMSE score for the high-TC group was significantly lower than that for the low-TC group $[\mathrm{t}(218)=3.425, \mathrm{p}=0.000]$. The CDR-Global score $[\mathrm{t}(218)=2.939, \mathrm{p}=0.004]$ and the CDR-SB score $[\mathrm{t}(218)=3.064, \mathrm{p}=0.003]$ were both significantly higher in the high-TC group, indicating greater impairment. The analysis of variance revealed that individuals with TC $\geq 200$ $\mathrm{mg} / \mathrm{dl}$ were reported to have a significantly higher total number of NPS than those with TC $<200 \mathrm{mg} / \mathrm{dl}[\mathrm{F}(1,218)=3.90, \mathrm{p}=0.007]$ and had more reported symptoms of psychosis $[\mathrm{F}(1$, $218)=8.046, p=0.005]$. The two groups did not differ in reported symptoms of hyperactivity, apathy or affect. 
Hall et al.: Total Cholesterol and Neuropsychiatric Symptoms in Alzheimer's Disease: The Impact of Total Cholesterol Level and Gender

Table 3. OR for the occurrence of NPS with high TC compared with low TC

\begin{tabular}{|c|c|c|c|c|c|c|}
\hline & \multicolumn{2}{|l|}{ Total sample } & \multicolumn{2}{|l|}{ Male } & \multicolumn{2}{|l|}{ Female } \\
\hline & OR (95\% CI) & $\mathrm{p}$ value & OR $(95 \% \mathrm{CI})$ & $\mathrm{p}$ value & OR (95\% CI) & $\mathrm{p}$ value \\
\hline NPS total & $1.24(1.12-3.63)$ & 0.657 & $2.03(0.37-11.24)$ & 0.405 & $0.84(0.21-3.33)$ & 0.806 \\
\hline Hyperactivity & $2.02(1.04-3.10)$ & 0.017 & $2.70(0.85-8.50)$ & 0.082 & $2.25(1.07-4.72)$ & 0.029 \\
\hline Psychosis & $1.80(1.04-3.10)$ & 0.034 & $3.88(1.47-10.20)$ & 0.004 & $1.16(0.05-2.36)$ & 0.679 \\
\hline Affect & $1.23(0.69-2.17)$ & 0.472 & $2.47(0.91-6.71)$ & 0.071 & $0.65(0.31-1.37)$ & 0.265 \\
\hline Apathy & $1.06(0.60-1.86)$ & 0.823 & $3.27(1.20-8.86)$ & 0.017 & $0.67(0.31-1.42)$ & 0.296 \\
\hline
\end{tabular}

Table 2 presents the NPS by gender and TC level. The males did not differ from the females in any of the NPI variables. A significant main effect for cholesterol level was found for the total number of NPS $[F(1,216)=7.426, p=0.007]$, symptoms of hyperactivity $[F(1,216)=$ $4.346, p=0.038]$ and symptoms of psychosis $[F(1,216)=10.863, p=0.001]$. A significant gender $\times$ cholesterol interaction was found for the total number of $\operatorname{NPS}[F(1,216)=4.546$, $\mathrm{p}=0.034]$, symptoms of psychosis $[\mathrm{F}(1,216)=3.934, \mathrm{p}=0.049]$ and symptoms of affect $[\mathrm{F}(1$, 216) $=6.024, p=0.015]$.

To clarify these findings, the relationship between gender and cholesterol level was investigated. Analyses comparing the high-TC females with the high-TC males found that the females had significantly higher MMSE scores than the males [ $\mathrm{t}(131)=2.210, \mathrm{p}=0.028]$, but the two groups did not differ in CDR-Global score ( $p=0.745)$ or CDR-SB score $(p=0.4515)$. The low-TC females had significantly lower MMSE scores than the low-TC males [t(85) = $2.996, \mathrm{p}=0.004]$ and significantly higher CDR-SB scores than the low-TC males $[\mathrm{t}(85)=2.875$, $\mathrm{p}=0.005]$, although the low-TC groups did not differ in CDR-Global scores $(\mathrm{p}=0.092)$. When analyzing the female sample alone, there were no differences between the high-TC group and the low-TC group in the total number of NPS or any of the symptom factors, nor were differences found in MMSE, CDR-Global or CDR-SB scores.

Analyses comparing the high-TC males and the low-TC males revealed a different relationship. The MMSE scores were significantly different $[\mathrm{t}(74)=4.638, \mathrm{p}=0.0001]$, with the high-TC males having a mean score of 15.85 (SD = 7.459) and the low-TC males a mean score of $22.54(\mathrm{SD}=5.114)$. There was a significant difference between the groups in CDR-Global scores $[\mathrm{t}(74)=2.519, \mathrm{p}=0.014]$ and CDR-SB scores. The high-TC males had a mean CDR-SB score of 9.17 ( $S D=4.410$ ), while the low-TC males had a mean score of 5.52 [SD = 4.039; $\mathrm{t}(74)=3.709, \mathrm{p}=0.0004]$. The males in the high-TC group had a significantly higher total number of NPS $[\mathrm{t}(74)=2.855, \mathrm{p}=0.006]$, symptoms of psychosis $[\mathrm{t}(74)=3.245, \mathrm{p}=0.002]$ and symptoms of affect $[\mathrm{t}(74)=2.322, \mathrm{p}=0.023]$. There was a trend for males with $\mathrm{TC} \geq 200$ $\mathrm{mg} / \mathrm{dl}$ to have more symptoms of hyperactivity $(\mathrm{p}=0.080)$ and symptoms of apathy $(\mathrm{p}=$ 0.067), but these differences did not reach statistical significance.

Table 3 presents the OR for the presence and absence of NPS with TC $\geq 200 \mathrm{mg} / \mathrm{dl}$. For the overall sample, only symptoms of psychosis $(\mathrm{p}=0.034)$ and symptoms of hyperactivity $(p=0.017)$ were significantly related to cholesterol level. Individuals with high TC were 1.8 and 2 times more likely to have 1 or more symptoms of psychosis and of hyperactivity, respectively, than those with low TC. The OR for affective symptoms and symptoms of apathy suggest that the occurrence of these symptoms is not closely tied to cholesterol level when the total sample is considered.

The determination of the OR for the total occurrence of NPS was affected by the very small number of individuals who had no reported NPS. Given that the vast majority of individuals in the sample were reported to exhibit at least 1 NPS regardless of the cholesterol 
Table 4. OR comparing male AD subjects with low TC and those with high TC according to NPI items

\begin{tabular}{|c|c|c|c|}
\hline \multicolumn{4}{|c|}{ Dement Geriatr Cogn Disord 2014;38:300-309 } \\
\hline \multicolumn{2}{|l|}{ DOI: $10.1159 / 000361043$} & \multicolumn{2}{|c|}{$\begin{array}{l}\text { (c) } 2014 \text { S. Karger AG, Basel } \\
\text { www.karger.com/dem }\end{array}$} \\
\hline \multicolumn{4}{|c|}{$\begin{array}{l}\text { Hall et al.: Total Cholesterol and Neuropsychiatric Symptoms in Alzheimer's Disease } \\
\text { The Impact of Total Cholesterol Level and Gender }\end{array}$} \\
\hline & OR & $95 \% \mathrm{CI}$ & $\mathrm{p}$ value \\
\hline Hallucinations & 2.166 & $0.558-8.417$ & 0.256 \\
\hline Irritability & 1.385 & $0.547-3.512$ & 0.491 \\
\hline Motor activity & 5.138 & $1.708-15.464$ & $0.002^{*}$ \\
\hline Agitation & 1.792 & $0.650-4.063$ & 0.212 \\
\hline Delusions & 5.797 & $1.446-23.238$ & $0.007^{*}$ \\
\hline Depression & 1.588 & $0.632-3.989$ & 0.323 \\
\hline Anxiety & 3.186 & $1.238-8.205$ & $0.014^{*}$ \\
\hline Elation & 0.629 & $0.108-3.662$ & 0.604 \\
\hline Apathy & 2.239 & $0.884-5.671$ & 0.086 \\
\hline Disinhibition & 1.066 & $0.414-2.749$ & 0.896 \\
\hline \multicolumn{4}{|l|}{ Night-time behavioral } \\
\hline disturbances & 3.551 & $1.369-9.222$ & $0.008^{*}$ \\
\hline Appetite & 1.756 & $0.695-4.439$ & 0.231 \\
\hline
\end{tabular}

$* \mathrm{p}<0.05$.

level, the analyses were conducted based on comparing individuals with 3 or fewer symptoms (the approximate median number of NPS for the sample) and those reported to have 4 or more symptoms. The likelihood of having 4 or more symptoms was 2.173 (95\% CI: 1.2533.767; $\mathrm{p}=0.007$ ) times greater for the high-TC group.

The role of elevated cholesterol appears to be gender and symptom specific. When comparing the high-TC males with the high-TC females, the males were 2.66 (95\% CI: $1.142-$ $6.243 ; p=0.027$ ) times more likely than the females to have 4 or more NPS. The high-TC males were 2.78 (95\% CI: 1.023-7.544; $\mathrm{p}=0.045$ ) times more likely to have hyperactive symptoms, 2.34 (95\% CI: 1.001-5.453; $\mathrm{p}=0.049)$ times more likely to have affective symptoms and 2.58 (95\% CI: $1.052-6.216 ; p=0.038)$ times more likely to have symptoms of apathy than the high-TC females. There was no significant difference in the likelihood of having symptoms of psychosis.

For the males with elevated TC, the likelihood of having symptoms of psychosis significantly increased almost 4 times, and that of having symptoms of apathy over 3 times, compared with the males with lower cholesterol. Although not reaching significance, there was a trend suggesting a relationship between high TC in males and the occurrence of hyperactive and affective symptoms. The likelihood of high-TC males having 4 or more NPS was 4.5 times greater (95\% CI: 1.681-12.045; $\mathrm{p}=0.002)$ than for the low-TC group. For females, only symptoms of hyperactivity were significantly related to elevated cholesterol; thus, for the high-TC females, the likelihood of having 1 or more symptoms of hyperactivity increased 2.25 times $(\mathrm{p}=0.029)$ compared with the low-TC group. Neither symptoms of psychosis nor affective symptoms nor symptoms of apathy were significantly related to high cholesterol for this group. The likelihood of the high-TC females having 4 or more NPS was not significantly different from that for the low-TC females (OR = 1.452; 95\% CI: 0.7125-2.958; p = 0.303).

An analysis of the individual NPI symptoms revealed a significant main effect for TC level for symptoms of delusions $[F(1,216)=6.098, p=0.014]$, motor activity $[F(1,216)=10.131$, $\mathrm{p}=0.002]$ and night-time behavioral disturbances $[\mathrm{F}(1,216)=5.231, \mathrm{p}=0.023]$. There was a significant effect for gender only for symptoms of irritability $[F(1,216)=7.111, p=0.008]$, where significantly more symptoms were reported for males than for females. Significant level $\times$ gender interactions were found for symptoms of anxiety $[F(1,216)=6.543, p=0.011]$, apathy $[\mathrm{F}(1,216)=4.947, \mathrm{p}=0.027]$ and night-time behavioral disturbances $[\mathrm{F}(1,216)=$ $4.067, \mathrm{p}=0.045]$. Post hoc analyses of the impact of cholesterol level on specific symptoms 
revealed no significant differences between high- and low-TC females in any of the items. Compared with the low-TC males, the high-TC males were reported to have significantly more symptoms of delusions [ $\mathrm{t}(74)=2.735, \mathrm{p}=0.008]$, anxiety [ $\mathrm{t}(74)=2.502, \mathrm{p}=0.015]$, motor activity $[\mathrm{t}(74)=2.851, \mathrm{p}=0.006]$ and night-time behavioral disturbances $[\mathrm{t}(74)=3.152, \mathrm{p}=$ 0.002]. Table 4 presents the OR for each of the NPI items for the male sample. The high-TC males were over 5 times more likely to have reported symptoms of motor activity and delusions than the low-TC males. Symptoms of anxiety and night-time behavioral disturbances were over 3 times more likely.

\section{Discussion}

NPS in AD increase caregiver stress [27,28] and the likelihood of nursing home placement [29]. Many of the available pharmacological interventions for these symptoms either are potentially harmful or have an unproven effect [30]. Discovering the characteristics of individuals who are more likely to exhibit NPS could lead to the development of interventions to reduce their occurrence. The current findings provide support for serum cholesterol having a significant relation to the number and type of NPS in AD. The results suggest that borderlineto-high levels of total serum cholesterol are associated with NPS and that there are significant differences in the occurrence of NPS based on the level of cholesterol.

In our study, the high-TC group scored significantly lower on the MMSE and higher on measures assessing the stage of decline and functional impairment where higher scores indicate greater decline. An elevated serum cholesterol level has been shown to influence the rate of disease progression [31]. NPS in AD have been shown to slightly increase over the course of the disease [32] and to be relatively persistent [33, 34]. NPS, especially hallucinations and apathy [35], are also related to global functional impairment over time. It could be argued that our findings of greater global impairment and a higher number of NPS for the high-TC group reflects disease severity as much as any specific effect of cholesterol.

This position fails to account for the significant gender differences found in the relationship of cholesterol to NPS. In our study, the effect of cholesterol on the occurrence of NPS was greatly influenced by gender. Although the high-TC females had higher MMSE scores than the high-TC males, the two groups did not differ in their stage of decline or level of functional impairment. The females in our sample had significantly higher cholesterol, and a significantly higher percentage of them had TC $\geq 200 \mathrm{mg} / \mathrm{dl}$, yet the females and the males did not differ in the occurrence of NPS. The high-TC and the low-TC females did not differ in any of the NPS variables. The differences in NPS found with regard to cholesterol level appear to be driven by the high-TC males. This group had a significantly higher total number of NPS, symptoms of psychosis and symptoms of affect than the low-TC males.

The odds of having multiple NPS and symptoms of hyperactivity, apathy and affect were significantly higher for the high-TC males than for the high-TC females and the low-TC males. In our sample, the high-TC males were over 2 times more likely to have symptoms of hyperactivity (OR $=2.78, \mathrm{p}=0.045)$, affect (OR $=2.34, \mathrm{p}=0.049)$ and apathy (OR $=2.35, \mathrm{p}=0.048)$ than the rest of the total sample, regardless of gender or the TC group.

There are a number of limitations that may affect the generalizability of the findings. The size of the sample was relatively small, although the cohort is well characterized as an AD cohort. Analyzing by gender and grouping by cholesterol level further reduced the sample size. The study is cross-sectional, and conclusions would be strengthened by looking longitudinally at the impact of high cholesterol. Additionally, the cholesterol measurements were made on nonfasting samples and as such may not be representative of the actual circulating level. The initial TARCC protocol did not include the collection of data on the use of statins 
Hall et al.: Total Cholesterol and Neuropsychiatric Symptoms in Alzheimer's Disease: The Impact of Total Cholesterol Level and Gender

and other cholesterol-lowering medications, nor on the initiation or discontinuation of these medications. This is an important limitation and may have introduced a confound. This information is being collected in the ongoing cross-validation study, which will allow us to assess the impact of statin use. It is interesting to note that, in general, statin use is significantly lower among elderly women than among elderly men [36]. However, even in the absence of knowledge about medications, it could be shown that individuals with TC $\geq 200 \mathrm{mg} / \mathrm{dl}$ at the time of the assessment showed a significantly different pattern of NPS.

The current findings are suggestive of the importance of understanding the role of cholesterol and gender in the occurrence of NPS in AD. The mechanism by which high cholesterol appears to differentially impact males with regard to the occurrence of NPS is unclear and beyond the scope of the current research. Cross-validating these findings in larger samples will have significant implications for possible treatment interventions to reduce the occurrence of NPS in AD.

\section{Appendix}

Investigators from the TARCC: Baylor College of Medicine - Rachelle Doody, MD, PhD, Susan Roundtree, MD, Valory Pavlik, PhD, Wen Chan, PhD, Paul Massman, PhD, Eveleen Darby and Tracey Evans; Texas Tech University Health Science Center - Benjamin Williams, MD, Gregory Schrimsher, PhD, Andrew Dentino, MD, and Ronnie Orozco; University of North Texas Health Science Center - Thomas Fairchild, PhD, Janice Knebl, DO, Douglas Mains and Lisa Alvarez; University of Texas Southwestern Medical Center - Perrie Adams, PhD, Roger Rosenberg, MD, Myron Weiner, MD, Mary Quiceno, MD, Joan Reisch, PhD, Ryan Huebinger, PhD, Guanghua Xiao, PhD, Doris Svetlik, Amy Werry and Janet Smith; University of Texas Health Science CenterSan Antonio - Donald Royall, MD, Raymond Palmer, PhD, and Marsha Polk.

\section{Acknowledgements}

The research presented in this publication was supported by the National Institute on Aging of the National Institutes of Health (award No. R01AG039389 and P30AG12300). The content is solely the responsibility of the authors and does not necessarily represent the official views of the National Institutes of Health. This study was made possible by the TARCC funded by the state of Texas through the Texas Council on Alzheimer's Disease and Related Disorders. The funders had no role in the study design, data collection, analysis, decision to publish or preparation of the manuscript.

\section{Disclosure Statement}

The authors have no competing interests to report.

\section{References}

1 Kivipelto M, Helkala EL, Laakso MP, Hänninen T, Hallikainen M, Alhainen K, Soininen H, Tuomilehto J, Nissinen A: Midlife vascular risk factors and Alzheimer's disease in later life: longitudinal, population based study. BMJ 2001;322:1447-1451.

-2 Kivipelto M, Ngandu T, Fratiglioni L, Viitanen M, Kåreholt I, Winblad B, Helkala EL, Tuomilehto J, Soininen H, Nissinen A: Obesity and vascular risk factors at midlife and the risk of dementia and Alzheimer disease. Arch Neurol 2005;62:1556-1560.

-3 Whitmer RA, Sidney S, Selby J, Johnston SC, Yaffe K: Midlife cardiovascular risk factors and risk of dementia in late life. Neurology 2005;64:277-281.

4 Reiss AB, Siller KA, Rahman MM, Chan ES, Ghiso J, de Leon MJ: Cholesterol in neurologic disorders of the elderly: stroke and Alzheimer's disease. Neurobiol Aging 2004;25:977-989.

5 Shobab LA, Hsiung GY, Feldman HH: Cholesterol in Alzheimer's disease. Lancet Neurol 2005;4:841-452. 
Hall et al.: Total Cholesterol and Neuropsychiatric Symptoms in Alzheimer's Disease:

The Impact of Total Cholesterol Level and Gender

-6 Panza F, D’Introno A, Colacicco AM, Capurso C, Pichichero G, Capurso SA, Capurso A, Solfrizzi V: Lipid metabolism in cognitive decline and dementia. Brain Res Rev 2006;51:275-292.

7 Gamba P, Testa G, Sottero B, Gargiulo S, Poli G, Leonarduzzi G: The link between altered cholesterol metabolism and Alzheimer's disease. Ann NY Acad Sci 2012;1259:54-64.

-8 Pappolla MA, Bryant-Thomas TK, Herbert D, Pacheco J, Fabra Garcia M, Manjon M, Girones X, Henry TL, Matsubara E, Zambon D, Wolozin B, Sano M, Cruz-Sanchez FF, Thal LJ, Petanceska SS, Refolo LM: Mild hypercholesterolemia is an early risk factor for the development of Alzheimer amyloid pathology. Neurology 2003; 61:199-205.

9 Reitz C, Tang MX, Luchsinger J, Mayeux R: Relation of plasma lipids to Alzheimer disease and vascular dementia. Arch Neurol 2004;61:705-714.

10 Mielke MM, Zandi PP, Sjögren M: High total cholesterol levels in late life associated with a reduced risk of dementia. Neurology 2005;64:1689-1695.

-11 Stewart R, White LR, Xue QL, Launer LJ: Twenty-six-year change in total cholesterol levels and incident dementia: the Honolulu-Asia Aging Study. Arch Neurol 2007;64:103-107.

-12 Zuliani G, Cavalieri M, Galvani M, Volpato S, Cherubini A, Bandinelli S, Corsi AM, Lauretani F, Guralnik JM, Fellin $\mathrm{R}$, Ferrucci L: Relationship between low levels of high-density lipoprotein cholesterol and dementia in the elderly. The InChianti study. J Gerontol A Biol Sci Med Sci 2010;65:559-564.

13 Anstey KJ, Lipnicki DM, Low LF: Cholesterol as a risk factor for dementia and cognitive decline: a systematic review of prospective studies with meta-analysis. Am J Geriatr Psychiatry 2008;16:343-354.

14 Woods AG, Sokolowska I, Taurines R, Gerlach M, Dudley E, Thome J, Darie CC: Potential biomarkers in psychiatry: focus on the cholesterol system. J Cell Mol Med 2012;16:1184-1195.

15 Mathew A, Yoshida Y, Maekawa T, Kumar DS: Alzheimer's disease: cholesterol a menace? Brain Res Bull 2011; 86:1-12.

-16 Sánchez-Ferro A, Benito-León J, Mitchell AJ, Bermejo-Pareja F: A review of the potential therapeutic role of statins in the treatment of Alzheimer's disease: current research and opinion. Neuropsychiatr Dis Treat 2013; 9:55-63.

17 Niranjan R: Molecular basis of etiological implications in Alzheimer's disease: focus on neuroinflammation. Mol Neurobiol 2013;48:412-428.

18 Najjar S, Pearlman DM, Hirsch S, Friedman K, Strange J, Reidy J, Khoukaz M, Ferrell RB, Devinsky O, Najjar A, Zagzag D: Brain biopsy findings link major depressive disorder to neuroinflammation, oxidative stress, and neurovascular dysfunction: a case report. Biol Psychiatry 2014;75:e23-e26.

19 Hall JR, Wiechmann AR, Johnson LA, Edwards M, Barber RC, Winter AS, Singh M, O’Bryant SE: Biomarkers of cardiovascular risk, systemic inflammation and microvascular pathology to neuropsychiatric symptoms in Alzheimer's disease. J Alzheimers Dis 2013;35:363-371.

-20 Hall JR, Wiechmann AR, Johnson LA, Edwards ME, Barber RC, Cunningham R, Singh M, O’Bryant SE: The impact of APOE status on relationship of biomarkers of vascular risk and systemic inflammation to neuropsychiatric symptoms in Alzheimer's disease. J Alzheimers Dis 2014;40:887-896.

21 American Heart Association: What your cholesterol levels mean. December 10, 2012. http://www.heart.org/ HEARTORG/Conditions/Cholesterol/AboutCholesterol/What-Your-Cholesterol-Levels-Mean_UCM_305562_ Article.jsp (accessed November 2013).

-22 McKhann G, Drachman D, Folstein M, Katzman R, Price D, Stadlan EM: Clinical diagnosis of Alzheimer's disease: report of the NINCDS-ADRDA Work Group under the auspices of Department of Health and Human Services Task Force on Alzheimer's disease. Neurology 1984;34:939-944.

23 Kaufer DI, Cummings JL, Ketchel P, Smith V, MacMillan A, Shelley T, Lopez OL, DeKosky ST: Validation of the NPI-Q, a brief clinical form of the Neuropsychiatric Inventory. J Neuropsychiatry Clin Neurosci 2000;12:233239.

24 Aalten P, Verhey FR, Boziki M, Bullock R, Byrne EJ, Camus V, Caputo M, Collins D, de Deyn PP, Elina K, Frisoni G, Girtler N, Holmes C, Hurt C, Marriott A, Mecocci P, Nobili F, Ousset PJ, Reynish E, Salmon E, Tsolaki M, Vellas B, Robert PH: Neuropsychiatric syndromes in dementia. Results from the European Alzheimer Disease Consortium: part I. Dement Geriatr Cogn Disord 2007;24:457-463.

-25 O’Bryant S, Xiao G, Barber R, Reisch J, Hall J, Cullum CM, Doody R, Fairchild T, Adams P, Wilhelmsen K, DiazArrastia R: A blood-based algorithm for the detection of Alzheimer's disease. Dement Geriatr Cogn Disord 2011;32:55-62.

-26 O’Bryant S, Xiao G, Barber R, Cullum CM, Weiner M, Hall J, Edwards M, Grammas P, Wilhelmsen K, Doody R, Diaz-Arrastia R: Molecular neuropsychology: creation of test-specific blood biomarker algorithms. Dement Geriatr Cogn Disord 2014;37:45-57.

27 Allegri RF, Sarasola D, Serrano CM, Taragano FE, Arizaga RL, Butman J, Loñ L: Neuropsychiatric symptoms as a predictor of caregiver burden in Alzheimer's disease. Neuropsychiatr Dis Treat 2006;2:105-110.

28 Okura T, Langa KM: Caregiver burden and neuropsychiatric symptoms in older adults with cognitive impairment: the Aging, Demographics, and Memory Study (ADAMS). Alzheimer Dis Assoc Disord 2011;25: 116-121.

29 Tun SM, Murman DL, Long HL, Colenda CC, von Eye A: Predictive validity of neuropsychiatric subgroups on nursing home placement and survival in patients with Alzheimer disease. Am J Geriatr Psychiatry 2007;15: 314-327. 
-30 Lyketsos CG, Carrillo MC, Ryan JM, Khachaturian AS, Trzepacz P, Amatniek J, Cedarbaum J, Brashear R, Miller DS: Neuropsychiatric symptoms in Alzheimer's disease. Alzheimers Dement 2011;7:532-539.

-31 Samtani MN, Farnum M, Lobanov V, Yang E, Raghavan N, Dibernardo A, Narayan V: An improved model for disease progression in patients from the Alzheimer's Disease Neuroimaging Initiative. J Clin Pharmacol 2012; 52:629-644.

-32 Chow TW, Fridhandler JD, Binns MA, Lee A, Merrilees J, Rosen HJ, Ketelle R, Miller BL: Trajectories of behavioral disturbance in dementia. J Alzheimers Dis 2012;31:143-149.

-33 Vilalta-Franch J, López-Pousa S, Calvó-Perxas L, Garre-Olmo J: Psychosis of Alzheimer disease: prevalence, incidence, persistence, risk factors, and mortality. Am J Geriatr Psychiatry 2013;21:1135-1143.

34 Vilalta-Franch J, Calvó-Perxas L, Garre-Olmo J, Turró-Garriga O, López-Pousa S: Apathy syndrome in Alzheimer's disease epidemiology: prevalence, incidence, persistence, and risk and mortality factors. J Alzheimers Dis 2013;33:535-543.

35 Wadsworth LP, Lorius N, Donovan NJ, Locascio JJ, Rentz DM, Johnson KA, Sperling RA, Marshall GA: Neuropsychiatric symptoms and global functional impairment along the Alzheimer's continuum. Dement Geriatr Cogn Disord 2012;34:96-111.

36 Bhattacharjee S, Findley PA, Sambamoorthi U: Understanding gender differences in statin use among elderly Medicare beneficiaries: an application of decomposition technique. Drugs Aging 2012;29:971-980. 